Case Reports in
Gastroenterology
Case Rep Gastroenterol 2020;14:695-701

DOI: $10.1159 / 000511129$

Published online: December 15, 2020
(C) 2020 The Author(s)

Published by S. Karger AG, Basel www.karger.com/crg

This article is licensed under the Creative Commons Attribution-NonCommercial 4.0 International License (CC BY-NC) (http://www.karger.com/Services/OpenAccessLicense). Usage and distribution for commercial purposes requires written permission.

\title{
Surgery for Ampullary Cancer in a Patient with Pancreatic Lipomatosis Caused by Cystic Fibrosis
}

\author{
Nienke E. Vuurberg ${ }^{a} \quad I_{\text {salien Bakker }}^{a} \quad$ Anne Loes van den Boom ${ }^{a}$ \\ Robbert J. de Haas ${ }^{b}$ Evelien W. Duiker ${ }^{c}$ Marius C. van den Heuvel ${ }^{c}$ \\ Joost M. Klaase \\ aUniversity Medical Center Groningen, Department of Surgery, Division of \\ Hepato-Pancreato-Biliary Surgery and Liver Transplantation, University of Groningen, \\ Groningen, The Netherlands; bUniversity Medical Center Groningen, Department of \\ Radiology, University of Groningen, Groningen, The Netherlands; 'University Medical \\ Center Groningen, Department of Pathology, University of Groningen, Groningen, \\ The Netherlands
}

\section{Keywords}

Ampullary cancer · Cystic fibrosis · Lipomatosis · Pancreatic cancer · Surgery

\begin{abstract}
A patient with cystic fibrosis (CF) with pancreatic insufficiency presented with jaundice due to an ampullary tumour. CF is known for a higher incidence of gastrointestinal malignancies. The patient suffered from pancreatic insufficiency. At computed tomography (CT), pancreatic lipomatosis with absence of the pancreatic duct was seen. This is uncommon, also in patients with CF. During surgery, a total pancreatectomy was performed, because there was no possibility to construct a duct to mucosa anastomosis due to the absence of the pancreatic duct and more importantly the pancreas was already afunctional. The presence of lipomatosis increases the risk of leakage at the pancreaticojejunal anastomosis. Therefore, it is important to take this phenomenon, in this case already visible on the preoperative CT scan, into account during the workup for surgery.




\section{Case Reports in Gastroenterology}

Case Rep Gastroenterol 2020;14:695-701 DOI: $10.1159 / 000511129$

c) 2020 The Author(s). Published by S. Karger AG, Basel www.karger.com/crg

Vuurberg et al.: Pancreatic Lipomatosis Caused by Cystic Fibrosis?

\section{Introduction}

Cystic fibrosis (CF) is a genetic disorder arising from a defect in a gene which encodes the cystic fibrosis transmembrane conductance regulator (CFTR), a chloride channel that is widely distributed in epithelial surfaces. Defects in CFTR function may cause lung infection, bronchiectasis, pancreatic insufficiency, episodic intestinal obstruction, liver disease and male infertility due to CFTR expression on the epithelia in these organs [1, 2]. Furthermore, CF patients show a higher incidence of gastrointestinal malignancies, including cancer at the esophago-gastric junction, the biliary tract, small bowel, and colon [2,3]. CF is known for early death because of organ failure and malignancies; however, with improving medical treatment the survival has increased rapidly $[1,4]$.

In patients with $\mathrm{CF}$, pancreatic involvement starts in the embryological period. The chronic inflammation due to inadequate enzyme secretion with progressive pancreatic damage and bouts of pancreatitis cause atrophy subsequently followed by adipose and fibrous tissue replacement. Finally, this will lead to malfunction of the pancreas. Clinically, this results in steatorrhea, malabsorption, diabetes, and growth retardation $[4,5]$.

In the present case, a male CF patient presented with icterus caused by an ampullary tumour. Preoperative computed tomography (CT) showed a pancreas completely replaced by fat, which was confirmed during surgery. There was no possibility to construct a duct to mucosa anastomosis due to the absence of the pancreatic duct. Because of this, we decided to perform a total pancreatectomy instead of a pancreaticoduodenectomy. Pancreatic lipomatosis in patients with $\mathrm{CF}$ is uncommon but has occasionally been described [6]. Other causes, such as diabetes, insulin resistance, obesity, chronic pancreatitis, and pancreatic ductal obstruction due to stone or malignancy, are more often observed as the origin of pancreatic lipomatosis $[7,8]$.

The present case describes the course of a 38-year-old male patient with a medical history consisting of CF, bilateral lung transplantation, and pancreatic lipomatosis, who underwent total pancreatectomy for perioperatively confirmed ampullary cancer.

\section{Case Presentation}

A 38-year-old male presented with silent jaundice, without any other complaints. His medical history consisted of CF and segmental intestinal resection due to small bowel obstruction in his first year of life. In 2009, he developed both exocrine and endocrine pancreatic insufficiency, necessitating pancreatic enzyme replacement and the use of insulin therapy. A continuing deterioration of his lung function resulted in the need of a bilateral lung transplantation in 2018 from which he recovered clinically well. Recently, he was analyzed because of jaundice. We saw a slightly icteric man with a body mass index of $21 \mathrm{~kg} / \mathrm{m}^{2}$ and a serum bilirubin of $56 \mu \mathrm{mol} / \mathrm{L}$. Abdominal ultrasound revealed dilated intrahepatic bile ducts and common bile duct. CT confirmed an ampullary tumour of $30 \mathrm{~mm}$ with extension into the duodenum (Fig. 1a, b). There were no regional lymph node or signs of distant metastases. A particular finding on the preoperative CT scan was the replacement of the entire pancreas with fat (Fig. 1c). The pancreatic duct could not be visualized. Biopsy of the ampullary tumour revealed an intestinal type adenocarcinoma and therefore our patient was scheduled for a pancreatoduodenectomy. The patient received a single dose of long acting somatuline (120 mg) preoperatively. During the operation, we noticed a lipomatosed pancreas and following transection of the pancreas we could not identify a pancreatic duct in the fatty pancreatic tissue. 


\section{Case Reports in Gastroenterology}

Case Rep Gastroenterol 2020;14:695-701 DOI: $10.1159 / 000511129$

c) 2020 The Author(s). Published by S. Karger AG, Basel www.karger.com/crg

Vuurberg et al.: Pancreatic Lipomatosis Caused by Cystic Fibrosis?

Taking into consideration that there was no possibility to anastomose the pancreatic duct to the jejunum in a patient using immunosuppressive medication in whom we could not permit pancreatic leakage, and pancreatic insufficiency, which was already known before the operation, we decided to perform a total pancreatectomy with sparing of the splenic vessels. The postoperative course was uneventful and on the 9th postoperative day, the patient was discharged in a clinically good condition, with stable glucose levels and no change in his need for insulin. Pathological examination showed a microscopically radical resection of a pT3bN2(5/16)M0 carcinoma of the ampulla of Vater and a pancreas completely replaced by fat with only some leftover islets of Langerhans. The pancreatic duct could not be detected (Fig. 2, 3).

After multidisciplinary considerations, it was decided to not administer adjuvant chemotherapy. Follow-up at our department consists of CT of chest and abdomen once a year. Furthermore, a colonoscopy will be performed because of the known higher incidence of gastrointestinal malignancies in transplanted CF patients.

\section{Discussion}

The present case describes the course of a CF patient with ampullary cancer in a pancreas completely replaced by fat who underwent radical oncological resection. Pancreatic lipomatosis is a rare phenomenon in patients with CF. It is important to take this phenomenon, which was visible on the preoperative CT scan, into account during the workup for surgery. Apart from technical reasons rendering an anastomosis impossible without a visual pancreatic duct, the grave consequences of possible postoperative complications of pancreatic fistula in this immunosuppressed patient and the existing pancreatic insufficiency led to the decision to perform a total pancreatectomy. Of note, no pancreatic duct was visible during the operation, and therefore an anastomosis could not be performed. Despite the lack of evidence, we hypothesized that the presence of pancreatic lipomatosis increases the risk of leakage of the pancreaticojejunal anastomosis $[9,10]$. Usually, total pancreatectomy results in total exocrine pancreatic insufficiency and brittle diabetes. However, the patient described in the current case report was already diagnosed with both exocrine and endocrine pancreatic insufficiency. After the operation, he recovered very well with stable low blood glucose levels and almost no change in his need for insulin.

\section{Pathophysiology}

$\mathrm{CF}$, an autosomal recessive disease, is caused by mutations in the gene encoding the $\mathrm{CF}$ transmembrane conductance regulator (CFTR). In the pancreas, CFTR is expressed in the epithelial cells of the small pancreatic ducts and facilitates transport of chloride and bicarbonate into the ducts. Bicarbonate is a key buffer for pancreatic fluid, keeping pancreatic enzymes inactive and functioning as a neutralizer of gastric acid and subsequently providing an optimal $\mathrm{pH}$ for the function of digestive enzymes.

As a result, patients with CF have an altered composition of pancreatic secretions with reduced $\mathrm{pH}$, decreased volume, and higher content of proteins. These factors may lead to ductal obstruction, eventually leading to inflammation with reactive tissue destruction. In case of advanced disease, pancreatic function is lost, ultimately resulting in a destroyed pancreas containing only islets or rare ducts [11].

Due to these pathophysiological changes in CF patients, they have an increased risk to develop malignancies, in particular gastrointestinal cancers including malignancies at the 


\section{Case Reports in Gastroenterology}

\begin{tabular}{l|l}
\hline Case Rep Gastroenterol 2020;14:695-701 \\
\hline DOI: 10.1159/000511129 & $\begin{array}{l}\text { @ 2020 The Author(s). Published by S. Karger AG, Basel } \\
\text { www.karger.com/crg }\end{array}$ \\
\hline
\end{tabular}

Vuurberg et al.: Pancreatic Lipomatosis Caused by Cystic Fibrosis?

esophageal-gastric junction, the biliary tract, small bowel, and colon. Moreover, CF patients with a history of transplantation do have a higher incidence of cancer, especially colorectal cancer $[2,3,12]$. Therefore, in CF patients who underwent organ transplantation, screening with colonoscopy at younger age could be considered [12].

The pathophysiology of the development of cancer in CF patients is twofold. First, impaired electrolyte transport could lead to dysfunction of the mucosal barrier leading to bacterial colonization and mucosal inflammation which promote oncogenesis. On the other hand, CFTR deficiency could induce upregulation of oncogenetic genes [3].

The current patient had a higher risk of gastrointestinal cancer due to the known medical history consisting of $\mathrm{CF}$ and bilateral lung transplantation. He developed jaundice due to ampullary cancer, for which he was scheduled to undergo a pancreatoduodenectomy. Creating a pancreatojejunal anastomosis as part of this operation was deemed especially risky in a CF patient with pancreatic lipomatosis who was also receiving immunosuppressive treatment due to a previous lung transplantation. It is important to be aware of this risk to individualize the operation plan and provide proper preoperative counseling.

\section{Statement of Ethics}

The medical data used to create this paper has been anonymized. Besides, the patient signed informed consent for publication including images of his individual patient data. Research was conducted ethically in accordance with the World Medical Association Declaration of Helsinki.

\section{Conflict of Interest Statement}

None of the authors have disclosures to report.

\section{Funding Sources}

We did not receive any funding creating this manuscript.

\section{Author Contributions}

N.V.: Part of treatment team, writing of the manuscript. I.B.: Part of treatment team, writing of the manuscript. A.B.: Part of treatment team, framing this manuscript, editing of the manuscript. J.K.: Part of treatment team, framing this manuscript, editing of the manuscript. R.H.: Radiology, providing figures and editing of the manuscript. E.D.: Pathology, providing figures and editing of the manuscript. M.H.: Pathology, providing figures and editing of the manuscript. 


\section{Case Reports in Gastroenterology}

\begin{tabular}{l|l}
\hline DOI: $10.1159 / 000511129$ & (c) 2020 The Author(s). Published by S. Karger AG, Basel
\end{tabular} www.karger.com/crg

Vuurberg et al.: Pancreatic Lipomatosis Caused by Cystic Fibrosis?

\section{References}

1 Jain S, Davis P. Epidemiology of Viral Pneumonia. Clin Chest Med. 2017 Mar;38(1):1-9.

2 Maisonneuve P, Marshall BC, Knapp EA, Lowenfels AB. Cancer risk in cystic fibrosis: a 20-year nationwide study from the United States. J Natl Cancer Inst. 2013 Jan;105(2):122-9.

3 Yamada A, Komaki Y, Komaki F, Micic D, Zullow S, Sakuraba A. Risk of gastrointestinal cancers in patients with cystic fibrosis: a systematic review and meta-analysis. Lancet Oncol. 2018 Jun;19(6):758-67.

4 Granados A, Chan CL, Ode KL, Moheet A, Moran A, Holl R. Cystic fibrosis related diabetes: Pathophysiology, screening and diagnosis. J Cyst Fibros. 2019 Oct;18 Suppl 2:S3-9.

5 Piskin FC, Yavuz S, Kose S, Cagli C, Dogruel D, Tumgor G, et al. A comparative study of the pancreas in pediatric patients with cystic fibrosis and healthy children using two-dimensional shear wave elastography. J Ultrasound. 2020 Feb. https://doi.org/10.1007/s40477-020-00432-3.

6 Feigelson J, Pécau Y, Poquet M, Terdjman P, Carrère J, Chazalette JP, et al. Imaging changes in the pancreas in cystic fibrosis: a retrospective evaluation of 55 cases seen over a period of 9 years. J Pediatr Gastroenterol Nutr. 2000 Feb;30(2):145-51.

7 Mandavdhare HS, Kumar A, Sharma V, Rana SS. Pancreatic lipomatosis in cystic fibrosis: rare manifestation of an uncommon disease. Intractable Rare Dis Res. 2017 May;6(2):150-1.

8 Coulier B. Pancreatic Lipomatosis: An Extensive Pictorial Review. J Belg Soc Radiol. 2016 February; 100(1)(39).

9 Søreide K, Labori KJ. Risk factors and preventive strategies for post-operative pancreatic fistula after pancreatic surgery: a comprehensive review. Scand J Gastroenterol. 2016 Oct;51(10):1147-54.

10 Hartwig W, Gluth A, Hinz U, Bergmann F, Spronk PE, Hackert T, et al. Total pancreatectomy for primary pancreatic neoplasms: renaissance of an unpopular operation. Ann Surg. 2015 Mar;261(3):537-46.

11 Gibson-Corley KN, Meyerholz DK, Engelhardt JF. Pancreatic pathophysiology in cystic fibrosis. J Pathol. 2016 Jan;238(2):311-20.

12 Hadjiliadis D, Khoruts A, Zauber AG, Hempstead SE, Maisonneuve P, Lowenfels AB, et al.; Cystic Fibrosis Colorectal Cancer Screening Task Force. Cystic Fibrosis Colorectal Cancer Screening Consensus Recommendations. Gastroenterology. 2018 Feb;154(3):736-745.e14. 

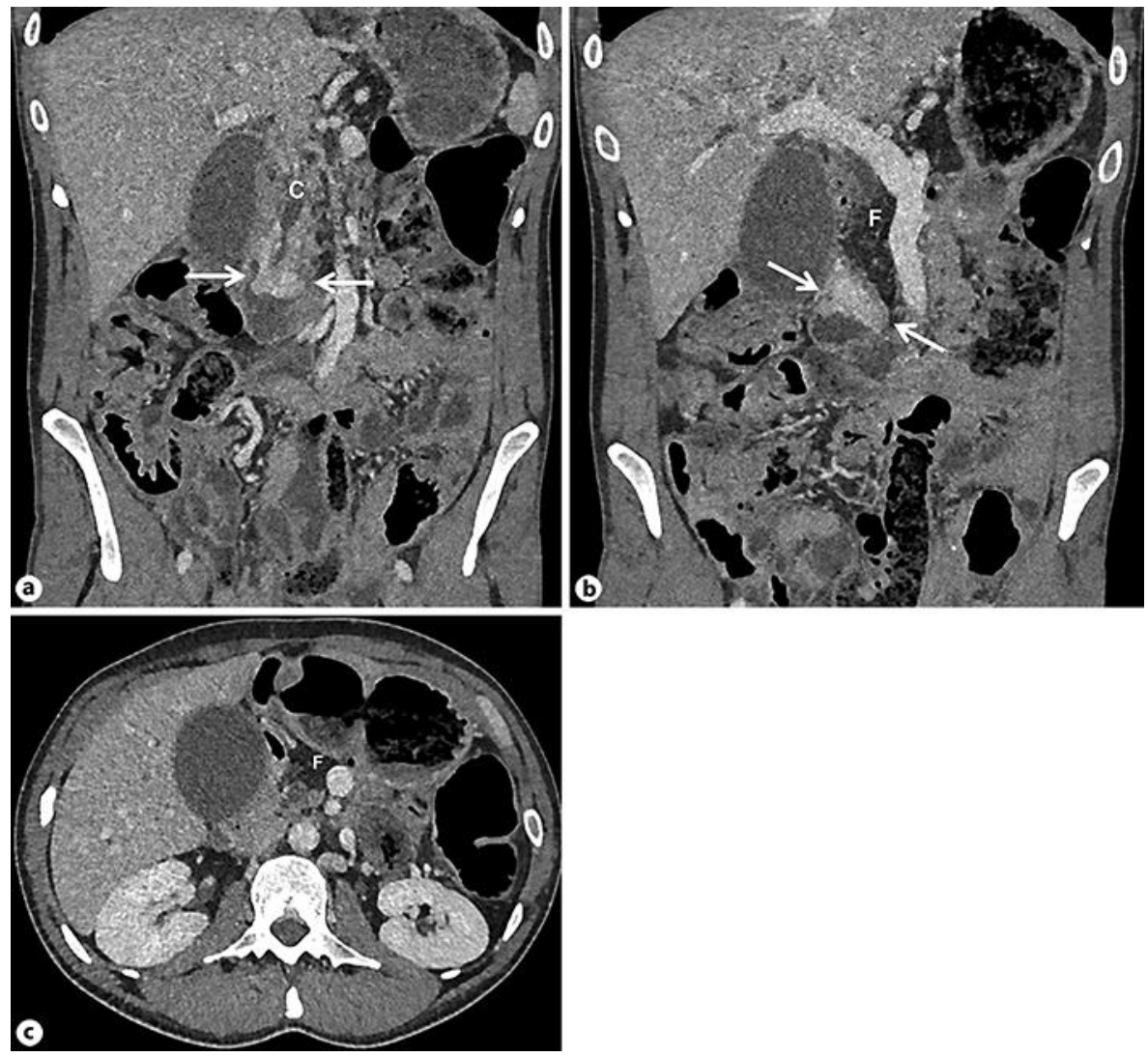

Fig. 1. a-c Computed tomography images ( $\mathbf{a}$ and $\mathbf{b}$ in coronal direction, and $\mathbf{c}$ in transverse direction) in the portal venous phase showing a large enhancing mass (between arrows in images a and $\mathbf{b}$ ) located at the ampulla of Vater (histologically proven adenocarcinoma), causing dilation of the common bile duct (indicated with " $\mathrm{C}$ " in image a) and intrahepatic bile ducts. The entire pancreas has been replaced by fat (indicated with " $F$ " in images $\mathbf{b}$ and $\mathbf{c}$ ), and the pancreatic duct could not be visualized.

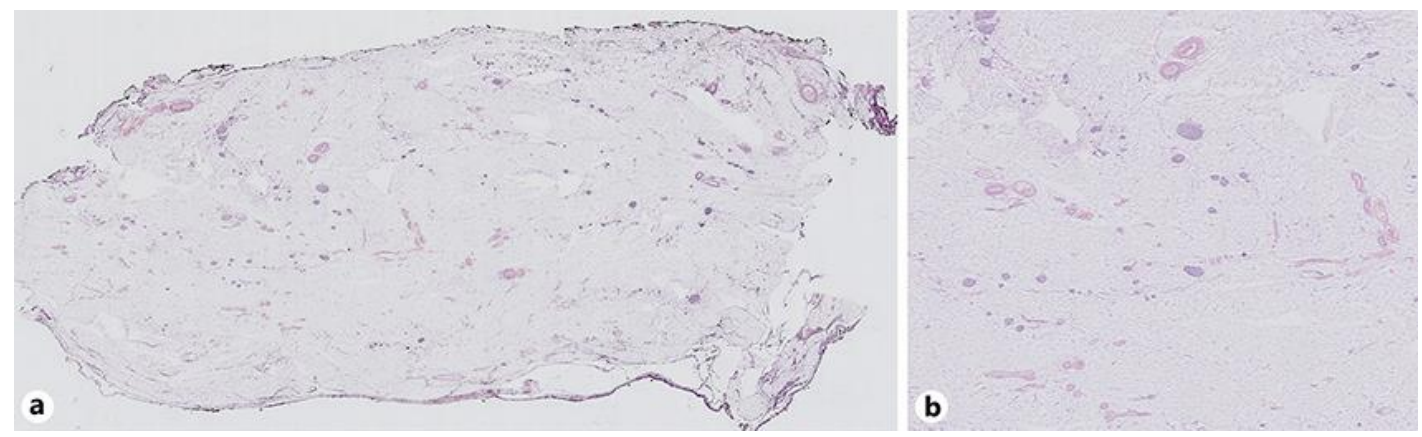

Fig. 2. a, b Pancreas: complete loss of acinar and ductular architecture with lipomatosis. b Dispersed preexisting islets. In a, an overview (zoom $0.25 \times$, digital image) and in $\mathbf{b}$ a detail (zoom $1 \times$, digital image) are shown. 
Case Reports in Gastroenterology
Case Rep Gastroenterol 2020;14:695-701

DOI: $10.1159 / 000511129$

(C) 2020 The www.karger.com/crg

Vuurberg et al.: Pancreatic Lipomatosis Caused by Cystic Fibrosis?
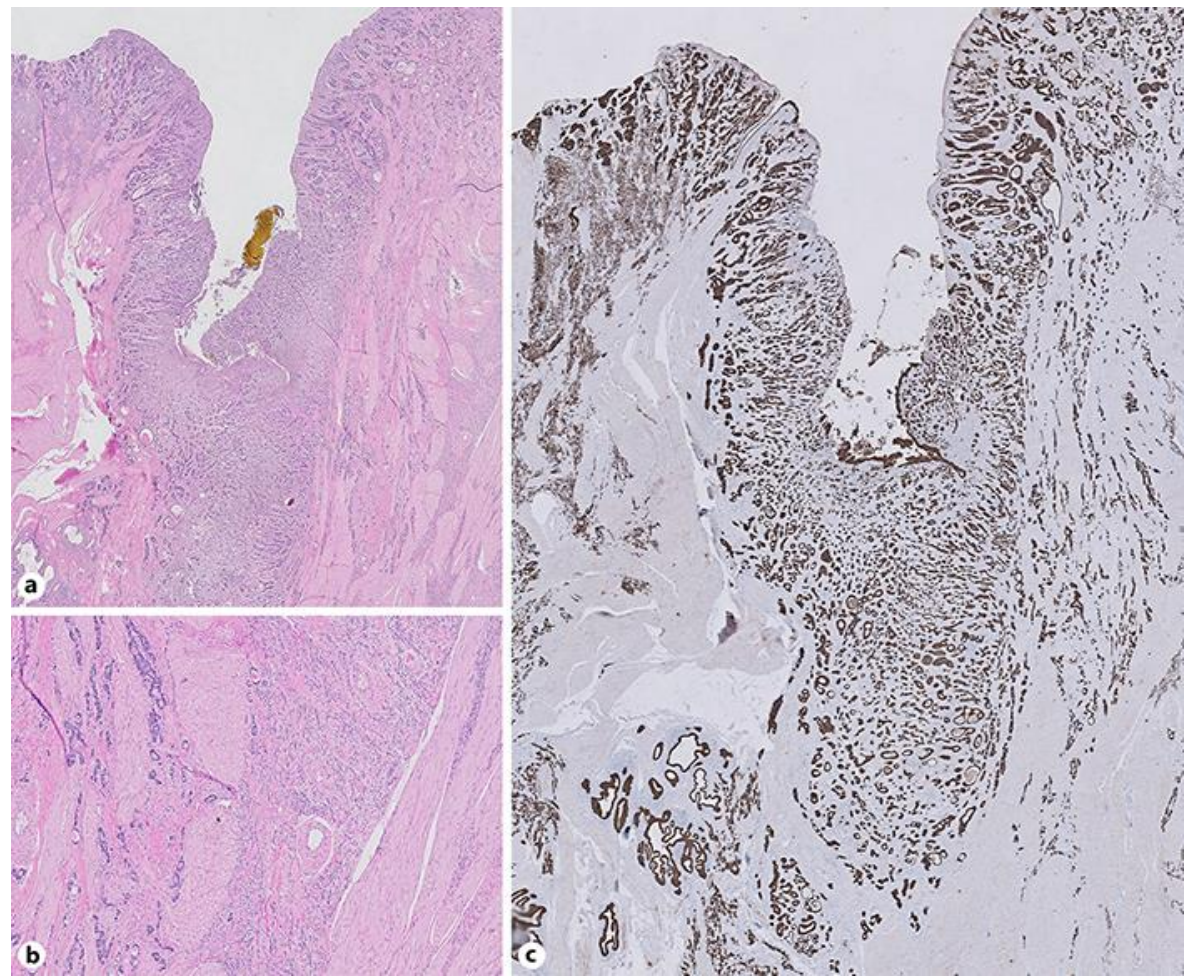

Fig. 3. a Overview (zoom $1 \times$ digital image) and b detail (zoom $5 \times$ digital image) of the tumor ampullary region: in the ampullary region, the presence of a tumor with biphasic aspect can be observed. Both glandular differentiation and undifferentiated phenotype with single, plasmacytoid cells coexisted. Both parts were diffusely positive with cytokeratin $\mathrm{AE} / 1$ (c). 